\title{
Mechanical properties and thermal expansion behaviour in leucite containing materials
}

\author{
TZER-SHIN SHEU, W. J. O'BRIEN*, S. T. RASMUSSEN*, \\ TSENG - YING TIEN \\ Department of Materials Science Engineering, School of Engineering, and *Department of \\ Biologic and Materials Sciences, School of Dentistry, The University of Michigan, Ann Arbor, \\ MI 48109, USA
}

The effect of a change in sodium content and thermal history on a leucite composition material produced by a coprecipitation process was studied. Five materials with formulae of $\left(\mathrm{K}_{(1-x)}, \mathrm{Na}_{x}\right)_{2} \mathrm{O} \cdot \mathrm{Al}_{2} \mathrm{O}_{3} \cdot 4 \mathrm{SiO}_{2}(x=0.0,0.2,0.4,0.6,0.8)$ were investigated for differences in phases, thermal expansion, and strength. Strengths of up to $175 \mathrm{MPa}$ were obtained for a leucite composition material $(x=0.0)$. Sodium was effective in lowering the thermal expansion coefficients of these materials. Leucite was linked to higher flexural strengths, but was present only in those specimens which were sintered at $1200^{\circ} \mathrm{C}$. Leucite was not present in those specimens sintered at $1100^{\circ} \mathrm{C}$ or lower. Porosity was present in all specimens sintered at $1000^{\circ} \mathrm{C}$ or higher.

\section{Introduction}

The public's desire for aesthetic restorations has been a strong motivating force for the development of ceramics for use as crowns and bridges. While traditional ceramic-metal crowns and bridges are aesthetic and the most long-lasting of the full-coverage restorative materials, all-ceramic crowns are generally more aesthetic. Unfortunately, current all-ceramic crowns are susceptible to mechanical failure [1-3]. Dental ceramics with flexural strengths in the range 140-150 MPa can be used for anterior crowns and give an adequate clinical success rate. However, when used for posterior crowns the failure rate $(15.2 \%$ over 7 years) is unacceptable [3]. McLean [3] has hypothesized that strengths as high as $500 \mathrm{MPa}$ may be required of ceramics used for all-ceramic posterior crowns. The strongest ceramic currently in use has a flexural strength of $152 \mathrm{MPa}$ [4]. Consequently, there is a need to develop stronger dental ceramics for use in posterior crowns.

Leucite-glass composites are likely candidates for new stronger materials for use in posterior ceramic crowns. Feldspar, a leucite glass composite, is a primary component of the porcelains used in traditional ceramic-metal restorations $[5,6]$. These porcelains have excellent aesthetics and biocompatibility [7]. Unfortunately their strengths (90 MPa) [8] are too low for all-ceramic crowns. Some leucite-glass composite's (not dental porcelains) have been found by Rouf et al. [9] to have strengths in the range 200-300 MPa. Morena et al. [10] noted that leucite containing dental porcelain had a higher fracture toughness than a leucite-free one (1.3 compared to $0.9 \mathrm{MNm}^{-3 / 2}$ ), which suggests that the presence of leucite can strengthen these porcelains. These findings are consistent with the theory, proposed by Hasselman and Fulrath [11], that the strength of a composite will increase as the volume fraction of the dispersed phase (leucite) increases and as the particle size of the dispersed phase decreases. Based upon this theory, the phase diagram for leucite and silica [12], and the cooling characteristics of leucite and its equilibrium liquids from high temperatures $[5,6,13,14]$, it should be possible to produce leucite-glass composites with a wide range of strengths (possibly as high as $300 \mathrm{MPa}$ ) [9] by varying the composition.

Leucite exists as two polymorphs. The stable form of leucite at high temperatures is cubic (high leucite) and as it cools there is a phase transformation to tetragonal (low leucite) in the range $500-600^{\circ} \mathrm{C}[5,6$, 13]. The presence of high leucite in dental porcelains is difficult to obtain at room temperature. Mackert et al. [6] found that high leucite was not a likely by-product of normal multiple firings.

Despite the potential for leucite to strengthen dental porcelains, most research has been directed at determining the effect that leucite has on the thermal expansion coefficient of these materials, because of the need for their coefficients to match the higher coefficients of the metal substrate. The low-temperature form of leucite has been identified as the material responsible for the high thermal expansion coefficient of dental porcelains $[5,13,15]$. The leucite content and, subsequently, the coefficient of thermal expansion of these materials has been found to change with thermal treatment $[5,13,16]$. Mackert and Evans [16] determined that various heat treatments could significantly alter the leucite content of a dental porcelain. Rouf 
et al. [9] found the thermal expansion coefficient of leucite to be as high as $25 \times 10^{-6}{ }^{\circ} \mathrm{C}^{-1}$.

It is likely that the strongest leucite-glass composites will have a high volume fraction of leucite which could lead to two major problems for dental porcelains. First, a high volume fraction of leucite would be coupled with a low volume fraction of the glass phase and, subsequently, the translucency will be low or non-existent. Translucency is an important property for dental porcelains in order that they have an aesthetic appearance [3]. This problem could be alleviated by ultrastructural processing of leuciteglass composites using a coprecipitation technique. This method can produce crystalline phases with dimensions in the $0.002-0.1 \mu \mathrm{m}$ range which is much smaller than is obtained by traditional methods [17]. The small size of the crystalline phase makes a crystalline-glass composite much more translucent because the crystalline size is smaller than the wavelength of light [17]. Leucite-glass composites, with high volume fractions of leucite and with the needed translucency, could likely be produced using this technique. A second problem is that a leucite-glass composite with a high volume fraction of leucite will also have a high coefficient of thermal expansion $[5,13$, 15]. The most aesthetic restorations are made with layers of porcelains which have different amounts of translucency and different colours [3]. Each of these layers must have compatible coefficients of thermal expansion in order to avoid crazing or chipping. Traditionally, when a manufacturer wanted to reduce the thermal expansion of a particular formulation for a dental porcelain they melted a low thermal expansion soda (Na) glass with the original formulation to produce a new material with a lower thermal expansion coefficient [18].

The purpose of this investigation was to compare a synthetic leucite $\left(\mathrm{K}_{2} \mathrm{O} \cdot \mathrm{Al}_{2} \mathrm{O}_{3} \cdot 4 \mathrm{SiO}_{2}\right)$ with other materials produced by a systematic substitution of sodium for potassium in this leucite, where all compounds were produced by a coprecipitation process. In particular, these materials were compared for differences in phases, thermal expansion, and strength.

\section{Experimental procedure}

The compositions of the synthetic materials studied are given by $\left(\mathrm{K}_{(1-x)}, \mathrm{Na}_{x}\right)_{2} \mathrm{O} \cdot \mathrm{Al}_{2} \mathrm{O}_{3} \cdot 4 \mathrm{SiO}_{2}$ where $x$ $=0.0,0.2,0.4,0.6$, and 0.8 . A coprecipitation method, which gives ion-scale mixing of each constituent, was used to make powders of the synthetic materials. An acid solution was made with appropriate amounts of $\mathrm{Al}\left(\mathrm{NO}_{3}\right)_{3} \cdot 9 \mathrm{H}_{2} \mathrm{O}$ (Aldrich Chemical Co., Inc., Milwaukee, WI) and $99 \%$ pure $\mathrm{Si}\left(\mathrm{C}_{2} \mathrm{H}_{5} \mathrm{O}\right)_{4}$ (Johnson Matthey/Alfa Products, Ward Hill, MA) mixed with ethyl alcohol. A base solution was made consisting of appropriate amounts of $\mathrm{KOH}$ and $\mathrm{NaOH}$. The base solution was added to the acid and mixed for an hour before $\mathrm{NH}_{4} \mathrm{OH}$ was added, drop by drop, to the solution until it became neutral. In order for potassium and sodium uniformly to coat the precipitate surface, the mixture was continuously stirred while drying under an infrared light. Dried powders were then calcined at $600^{\circ} \mathrm{C}$ in a platinum crucible at atmospheric pressure for $1 \mathrm{~h}$ in a muffle furnace. The calcination temperature was selected as a result of a differential thermal analysis (DTA) and a thermogravimetric analysis (TGA). The dried powders showed no chemical reaction or weight loss between 700 and $1100^{\circ} \mathrm{C}$. The calcined powders were ground in an agate jar with agate balls using a planetary mill. Pellets of $50 \mathrm{~mm}$ size were die-pressed from the ground powders and, subsequently, pressed isostatically at $310 \mathrm{MPa}$. The pellets were sintered at various temperatures for $1 \mathrm{~h}$ at atmospheric pressure and allowed to furnace cool. The specimens were sectioned from these pellets for the various tests.

The phases present in the specimens at room temperature were identified with an $\mathrm{X}$-ray diffractometer (XRD). Flexural strengths were determined from specimens with dimensions of $3.0 \mathrm{~mm} \times 2.0 \mathrm{~mm}$ $\times 25.0 \mathrm{~mm}$. The specimens were tested at a strain rate of $1 \times 10^{-4} \mathrm{~s}^{-1}$ using a four-point flexure fixture with an inner span of $5 \mathrm{~mm}$ and an outer span of $10 \mathrm{~mm}$. A dilatometer was used to determine the sintered materials' thermal expansion characteristics at heating and cooling rates of $10^{\circ} \mathrm{C} \mathrm{min}^{-1}$.

\section{Results and discussion}

The sintering temperature had a strong effect on the flexural strength for materials with $x_{\mathrm{Na}}=0.2$ (Fig. 1). XRD showed that the specimens, which were sintered at temperatures up to $1100^{\circ} \mathrm{C}$, had a glassy structure. Specimens, which were sintered at $1200^{\circ} \mathrm{C}$, were a leucite-glass composite. An optical microscope examination of the specimens revealed that those sintered at $950^{\circ} \mathrm{C}$ were fully dense but for those sintered at higher temperatures porosity was evident. Most likely the lower strengths of those specimens sintered at $1050^{\circ} \mathrm{C}$ and $1100^{\circ} \mathrm{C}$ were due to this porosity. Despite the presence of porosity, the specimens sintered at $1200^{\circ} \mathrm{C}$ were stronger than those sintered at $1050^{\circ}$ and $1100^{\circ} \mathrm{C}$. Most likely this increase in strength was due to the presence of leucite. The presence of porosity for those specimens sintered from $1000-1200^{\circ} \mathrm{C}$ suggests that a chemical reaction took place that was not detectable during DTA and TGA experiments, and suggests that higher calcination temperatures and/or longer times for calcination may be required. Additionally, vacuum firing during sintering may help reduce porosity and, subsequently, improve the strength of these materials.

Fig. 2 shows the data for flexural strength versus sodium content. Sodium has a pronounced negative effect on the strengths of the materials studied. Fig. 3 gives $X$-ray diffraction patterns for specimens with different amounts of sodium. It shows that as the sodium content increased the amount of leucite in the specimens decreased while the glassy phase increased. The results depicted in Fig. 2 are consistent with the theory of Hasselman and Fulrath [11] and the findings of Rouf et al. [9]. That is, as the volume per cent of the dispersed phase (leucite) was decreased, the strength was decreased. 


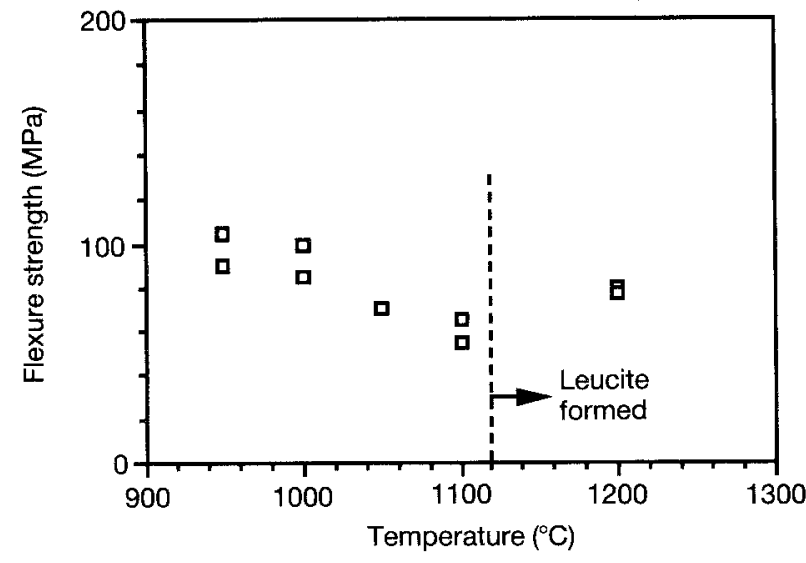

Figure I Flexural strength versus sintering temperature for samples with compositions of $\left(\mathrm{K}_{0 \cdot 8}, \mathrm{Na}_{0 \cdot 2}\right)_{2} \mathrm{O} \cdot \mathrm{Al}_{2} \mathrm{O}_{3} \cdot 4 \mathrm{SiO}_{2}$. The powders were calcined at $600^{\circ} \mathrm{C}$.

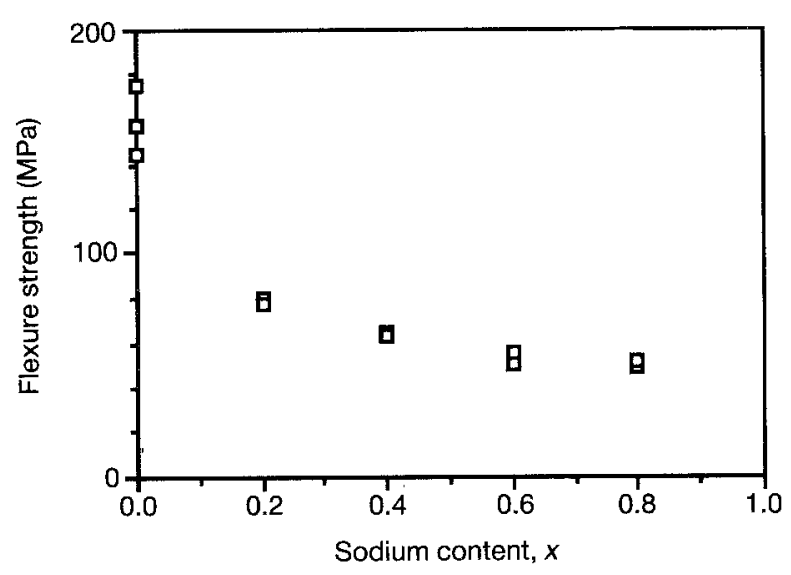

Figure 2 Flexural strength versus sodium content for samples with compositions of $\left(\mathrm{K}_{(1-x)}, \mathrm{Na}_{x}\right)_{2} \mathrm{O} \cdot \mathrm{Al}_{2} \mathrm{O}_{3} \cdot 4 \mathrm{SiO}_{2}$. Powders were calcined at $600^{\circ} \mathrm{C}$ and sintered at $1200^{\circ} \mathrm{C}$ for $1 \mathrm{~h}$.

The thermal expansion versus temperature data for specimens having different sodium contents are given in Fig. 4. The curves are nearly linear over a relatively wide range of temperatures. Leucite is known to have a phase transformation from a tetragonal structure to a cubic structure in the range $500-600{ }^{\circ} \mathrm{C}[5,6,13]$, but no evidence for this transformation is evident in this figure. Yoon et al. [14] found an inflection point in thermal expansion versus temperature curves around $616^{\circ} \mathrm{C}$. They found that the inflection point was lower for leucite-glass composites containing additional silica. Possibly, sodium stabilizes the tetragonal form of leucite at higher temperatures for the materials considered here. The thermal expansion coefficients were $15 \times 10^{-6}, 10 \times 10^{-6}, 9 \times 10^{-6}$ and $11.2 \times 10^{-6}{ }^{\circ} \mathrm{C}^{-1}$ for $x_{\mathrm{Na}}=0.2,0.4,0.6$ and 0.8 , respectively, which are considerably lower than for leucite $\left(25 \times 10^{-6}{ }^{\circ} \mathrm{C}^{-1}\right)$ [9]. Materials with thermal expansion coefficients in the range of $13.5 \times 10^{-6}-14.5$ $\times 10^{-6}{ }^{\circ} \mathrm{C}^{-1}$ are considered to be compatible with those of metals used in current ceramic-metal restorations and with those of many dental porcelains $[6,13]$. If a high-strength leucite -glass composite with thermal expansion coefficients in this range could be developed, these materials would likely be compatible

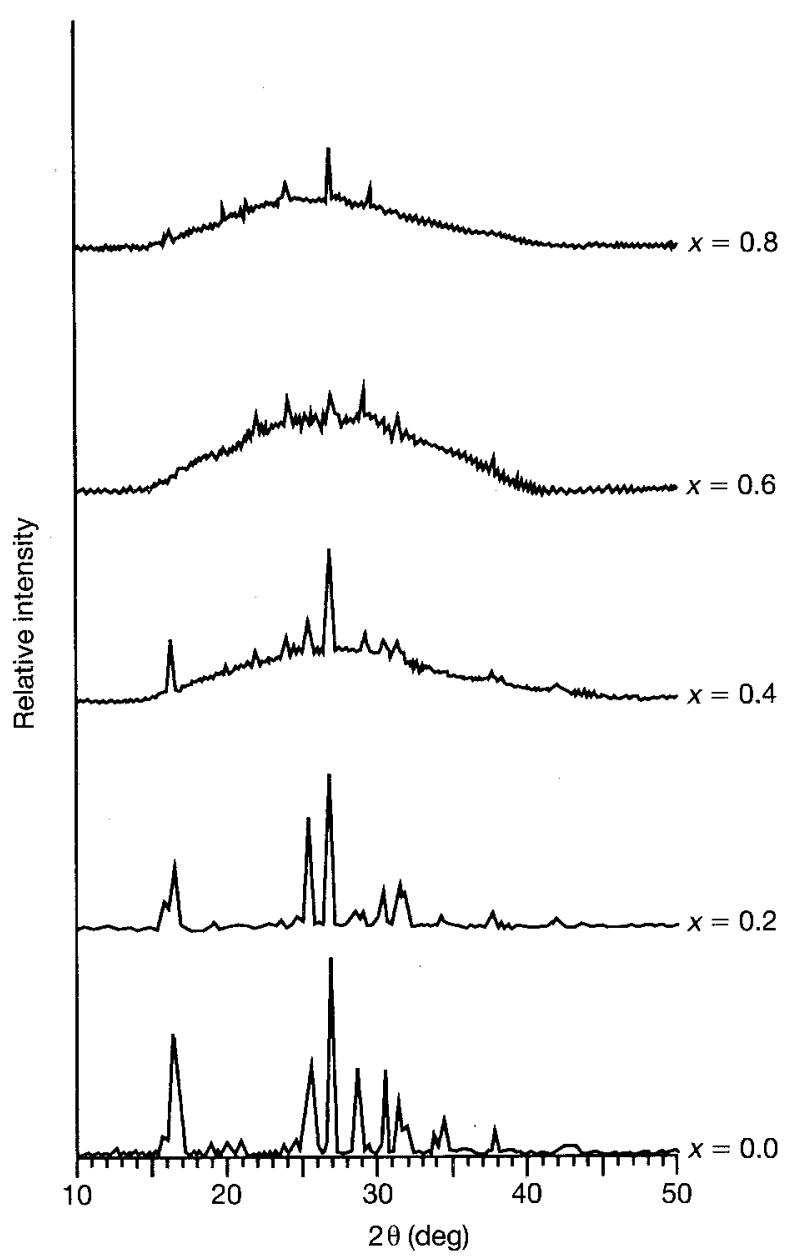

Figure $3 \mathrm{X}$-ray diffraction patterns for specimens with various compositions $\left(\mathrm{K}_{(1-x)}, \mathrm{Na}_{x}\right)_{2} \mathrm{O} \cdot \mathrm{Al}_{2} \mathrm{O}_{3} \cdot 4 \mathrm{SiO}_{2}(x=0.2,0.4,0.6,0.8)$. Powders were calcined at $600^{\circ} \mathrm{C}$ and sintered at $1200^{\circ} \mathrm{C}$ for $1 \mathrm{~h}$.

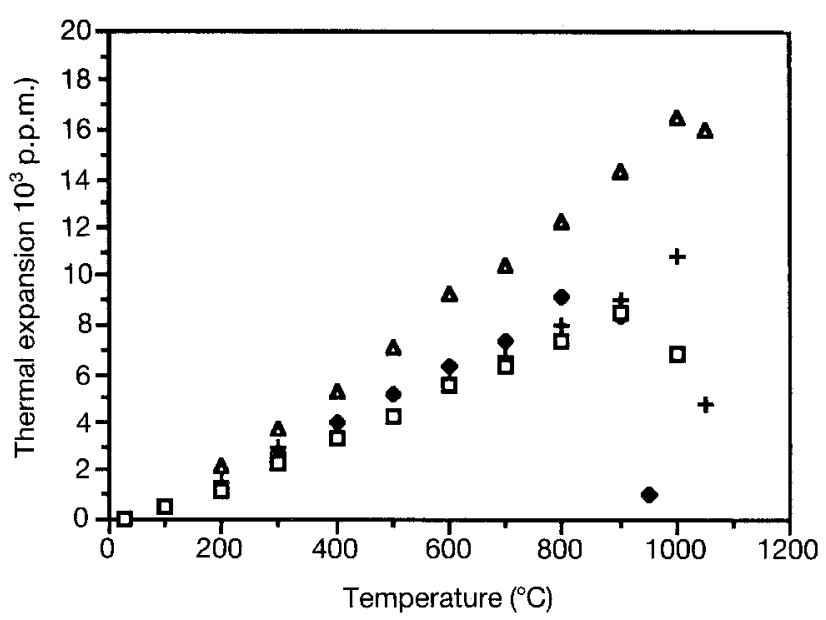

Figure 4 Thermal expansion versus temperature of specimens with various compositions $\left(\mathrm{K}_{(1-x)}, \mathrm{Na}_{x}\right)_{2} \mathrm{O} \cdot \mathrm{Al}_{2} \mathrm{O}_{3} \cdot 4 \mathrm{SiO}_{2}(x=(\triangle) 0.2$, $(+) 0.4,(\square) 0.6,(\diamond) 0.8)$. Powders were calcined at $600^{\circ} \mathrm{C}$ and sintered at $1200^{\circ} \mathrm{C}$ for $1 \mathrm{~h}$.

with some dental porcelains and metals and, thereby, reduce the number of different porcelains that would need to be developed.

The data suggest that high-strength materials containing leucite with appropriate thermal expansion coefficients are possible. The leucite composition specimens had strengths that ranged from 145- 
$175 \mathrm{MPa}$ (cf. data for $x=0.0$, Fig. 2) which, considering the porosity of the specimens, implies that improvements are possible. Additionally, sodium was effective in reducing thermal expansion coefficients of these materials.

\section{Conclusions}

1. Coprecipitation processing of materials having a formula of $\left(\mathrm{K}_{(1-x)}, \mathrm{Na}_{x}\right)_{2} \mathrm{O} \cdot \mathrm{Al}_{2} \mathrm{O}_{3} \cdot 4 \mathrm{SiO}_{2} \quad(x=0.0$, $0.2,0.4,0.6$ and 0.8 ) produced fine powders that would sinter at $950^{\circ} \mathrm{C}$ to produce dense samples which had a glassy structure.

2. Sintering at 1000,1050 and $1100^{\circ} \mathrm{C}$ produced porous specimens with reduced strengths.

3. Sintering at $1200^{\circ} \mathrm{C}$ produced porous specimens with leucite present and improved strengths.

4. Porous specimens with a leucite composition $\left(\mathrm{K}_{2} \mathrm{O} \cdot \mathrm{Al}_{2} \mathrm{O}_{3} \cdot 4 \mathrm{SiO}_{2}\right)$ had flexural strengths that ranged from $147-175 \mathrm{MPa}$.

5. Sodium was effective in lowering the thermal expansion coefficients of the materials it was added to, but also lowered their strengths.

\section{Acknowledgement}

This investigation was supported by USPHS Research Grant DE-09296 from the National Institute of Dental Research, National Institutes of Health, Bethesda, MD 20892.

\section{References}

1. D. W. JONES, Dent. Clin. N. Am. 29 (1985) 621.

2. W. J. O'BRIEN, J. Am. Dent. Assoc. 110 (1985) 548.

3. J. W. McLEAN, in "Dental Ceramics: Proceedings of the First
International Symposium on Ceramics", April 1982, edited by J. W. McLean (Quintessence, Chicago, IL 1983) pp. 13-40.

4. D. G. GR OSSMAN, in "Proceedings of Conference on Recent Developments in Dental Ceramics", Ann Arbor, October 1983, edited by W. J. O'Brien and R. G. Craig (Ceramic Engineering and Science Proceedings, American Ceramic Society, Columbus, OH, 1985) pp. 19-40.

5. C. W. FAIRHURST, K. J. ANUSAVICE, D. T. HASHINGER, R. D. RINGLE and S. W. TWIGGS, J. Biomed. Mater. Res. 14 (1980) 435.

6. J.R. MACKERT, Jr, M. B. BUTTS, R. MORENA and C. W. FAIR HURST, J. Am. Ceram. Soc. 69 (1986) C-69.

7. D. W. JONES, in "Biocompatibility of Dental Materials", Vol. IV, "Biocompatibility of Prosthodontic Materials", edited by D. C. Smith and D. F. Williams (CRC Press, Boca Raton, FL, 1982) pp. 79-122.

8. C. A. SHER RILL and W. J. O'BRIEN, J. Dent. Res. 53 (1974) 683.

9. M. A. ROUF, L. HERMANSSON and R. CARLSSON, Trans. J. Br. Ceram. Soc. 77 (1978) 36.

10. R. MORENA, P. E. LOCKWOOD, A. L. EVANS and C. W. FAIrhuRST, J. Am. Ceram. Soc. 64 (1986) C-74.

11. D. P. H. HASSELMAN and R. M. FULRATH, ibid. 49 (1966) 68.

12. M. K. RESER (ed.) "Phase Diagrams for Ceramists", (American Ceramic Society, Columbus, OH, 1964), p. 158, Fig. 412, pp. 265-266, Figs 786-789.

13. C. HAHN and C. TEUCHERT, Ceram. Forum Int. 57 (1980) 208.

14. C. K. YOON, S. T. RASMUSSEN, W. J. O'BRIEN and T. Y. TIEN, J. Mater. Res., submitted.

15. D. TAYLOR and C. M. B. HENDERSON, Am. Mineral. 53 (1968) 1476

16. J. R. MACKERT Jr and A. L. EVANS, J. Am. Ceram. Soc. $\mathbf{7 4}$ (1991) 450

17. L. L. HENCH and B. I. LEE, in "Encyclopedia of Science and Technology", edited by R. A. Meyers (Academic Press, Orlando, FL, 1987) pp. 210-19.

18. M. WEINSTEIN, S. KATZ and A. B. WEINSTEIN, US Pat. 3052982 and 3052983, 11 September 1962.

Received 28 July 1992

and accepted 8 June 1993 